\section{High-Resolution Mapping to Unmask and Localize Presystolic Purkinje Potentials During Idiopathic Verapamil-Sensitive Left Anterior Papillary Muscle Fascicular-Purkinje Ventricular Tachycardia}

Itsuro Morishima, $\mathrm{MD}, \mathrm{PhD}$;

Akihiko Nogami, MD, PhD; Yasunori Kanzaki, MD

A 20-year-old male with a structurally normal heart underwent catheter ablation (CA) for verapamilsensitive ventricular tachycardia (VT; Figure A). During VT, the left ventricle (LV) was mapped with a 3.5-mm-tip linear quadripolar catheter (Thermocool SF, Biosense Webster, Diamond Bar, CA, USA). No lowvoltage area was seen. The earliest activation occurred at the basal anterolateral LV area with a tiny Purkinje potential (PP; $0.05 \mathrm{mV}$ ), preceding the QRS by $35 \mathrm{~ms}$ (Figure A). The LV was then re-mapped with a 5 -spline 1 -mm electrode 20-pole 2-6-2-mm spacing PentaRay catheter (Biosense Webster), identifying an earlier $(-51 \mathrm{~ms})$ distinct highamplitude $(1.5 \mathrm{mV})$ presystolic PP followed by fractionated potentials at the medial surface of the anterior papillary muscle (APM) (Figure B). The entrainment study confirmed this site as an exit of the VT (Supplementary Figure), and left APM fascicular-Purkinje VT was diagnosed. ${ }^{1}$ Radiofrequency CA was successful.

Mapping with small, closely spaced multielectrode catheters can improve resolution within low-voltage areas and is expected to enhance CA for scar-related VTs. This case demonstrates the value of high-resolution PentaRay mapping to find critical PPs in left APM fascicular-Purkinje VT. In addition, the flexible splines may have played an important role in mapping the left anterior fascicular area including the APM, where varying perpendicular orientations are more likely with a linear catheter. The orientation of the bipole with a PentaRay is more likely to be in parallel with the endocardial tissue, and the thin splines may allow better access to small pouches. In this patient, the PentaRay was placed with 2 splines (Figure B white arrowheads) hugging the protruding APM, and the earliest PP during VT was recorded on one of the splines (Figure B).

\section{Conflict of Interest}

A.N.: Honoraria from Abbott and Biosense Webster and an endowment from Medtronic and DVx. I.M. and Y.K.: None.

\section{Funding}

None.

\section{Reference}

1. Komatsu Y, Nogami A, Kurosaki K, Morishima I, Masuda K, Ozawa $\mathrm{T}$, et al. Fascicular ventricular tachycardia originating from papillary muscles: Purkinje network involvement in the reentrant circuit. Circ Arrhythm Electrophysiol 2017; 10: e004549.

\section{Supplementary Files}

Please find supplementary file(s);

http://dx.doi.org/10.1253/circj.CJ-20-0597

Received June 8, 2020; revised manuscript received July 4, 2020; accepted July 23, 2020; J-STAGE Advance Publication released online October 3, 2020 Time for primary review: 21 days

Department of Cardiology, Ogaki Municipal Hospital, Ogaki (I.M., Y.K.); Cardiovascular Division, Faculty of Medicine, University of Tsukuba, Tsukuba (A.N.), Japan

Mailing address: Itsuro Morishima, MD, PhD, Department of Cardiology, Ogaki Municipal Hospital, 4-86 Minaminokawa-cho, Ogaki 503-8502, Japan. E-mail: morishima-i@muc.biglobe.ne.jp

All rights are reserved to the Japanese Circulation Society.

For permissions, please e-mail: cj@j-circ.or.jp

ISSN-1346-9843
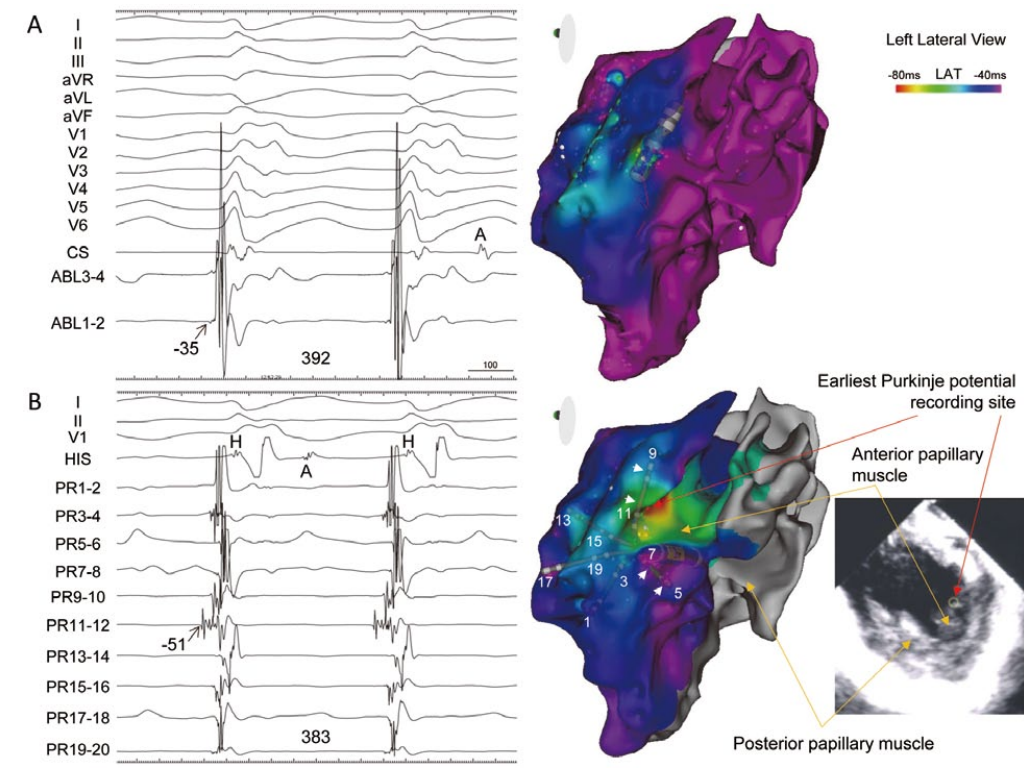

Figure. Local activation time mapping during ventricular tachycardia with a standard ablation $(A B L)$ catheter $(\mathbf{A})$ and a PentaRay (PR) (B) 